\title{
Understanding Appeals of Video Games for Readers' Advisory and Recommendation
}

Despite their increasing popularity and inclusion in library collections, video games are rarely suggested in library advisory or recommendation services. In this work, we use the concept of appeals from existing literature in readers' advisory and media studies to understand what attracts people to play certain games. Based on 1,257 survey responses, we identify sixteen different appeals of video games and elaborate how these appeals are expressed in users' terms. We envision these appeals can serve as an additional access point for video games and will be particularly useful for recommendation and advisory services. In addition, we also examined the correlation between appeals and common game genres. The relationships between appeals and genres observed from our data support our argument that appeals can serve as a complementary access point to result in more diversified sets of recommendations across genres. In our future work, we plan to further investigate individual appeals such as mood and narrative across multiple types of media.

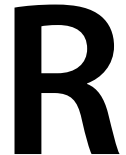
eaders' advisory (RA) has a long history in North American public libraries, dating back to the 1870s when the concept first emerged. ${ }^{1}$ The meaning of readers' advisory has evolved over time, from a focus on commitment to meaningful adult education via serious reading in the early twentieth century, to an emphasis on popular culture and users' entertainment starting around the 1960s. ${ }^{2}$ Since the 1950s, RA has been a core component of public library service. ${ }^{3}$ Currently, most RA work focuses on recommending books and audiobooks, not fully incorporating the library's collection in other formats. ${ }^{4}$ In particular, despite their increasing popularity and inclusion in library collections, video games are rarely suggested to patrons already interested in video gaming or as a crossmedia bridge. However, average users are format omnivores and consume a variety of different media. ${ }^{5}$ Given the importance of RA as a critical library service, we need a solid framework and guidelines for recommendations that include multiple formats and media types. Much of the research related to RA has been centered on "appeals": the idea that people are attracted to certain types of materials for different reasons. To support recommendation for diverse material formats, we need to investigate appeals for these formats. In our work, we collect and analyze empirical user data on what users perceive as the most important appeals of video games for themselves. We aim to answer the following research questions:

\section{Jin Ha Lee, Rachel Ivy Clarke, Hyerim Cho, and Travis Windleharth}

Jin Ha Lee (jinhalee@uw.edu) is Associate Professor, Information School, University of Washington, Seattle, Washington.

Rachel Ivy Clarke (rclark01@syr .edu) is Assistant Professor, School of Information Studies, Syracuse University, Syracuse, New York. Hyerim Cho (chohr113@uw.edu) is a PhD Candidate, Information School, University of Washington. Travis Windleharth (travisw@uw.edu) is a doctoral student, Information School, University of Washington.

Reference \& User Services Quarterly, vol. 57, no. 2, pp. 127-139 (c) 2017 American Library Association. All rights reserved.

Permission granted to reproduce for nonprofit, educational use. 


\section{FEATURE}

- What kinds of appeals can we identify for video games from people's description of their favorite games and reasons for liking them?

- How do appeals relate to currently established video game genres?

We anticipate that appeals identified in this study can potentially serve as additional metadata for video games in library catalogs and other recommendation systems. Understanding appeals for video games and their relationship to established genres can help improve the quality of recommendation services by enabling librarians to make suggestions with increased confidence. The findings may also have broader implications for appeals of other nontextual or multimedia that share similarities with video games (e.g., graphic materials, films), or are part of video games (e.g., music, animations).

\section{RELEVANT WORK}

\section{Defining Appeals}

Users seek various experiences when they interact with media objects, and recommendation aims to be a useful guide to these experiences. In libraries, RA is typically based on the idea of "appeals" - understanding different types of appeals and identifying which appeals matter to different users is widely recognized as a critical process for the success of RA work. ${ }^{6}$

Saricks, along with her colleague Nancy Brown, developed the concept of appeal as it applies to RA. Saricks explains "appeal" as "the elements of books to which a reader relates" or "the feel of a book." Appeals explicated in her work include pacing, characterization, story line, tone and mood, style and language, and frame and setting. Building on Saricks' work, Pearl uses the term doorways to refer to appeals specifically for fiction-story, character, setting, and language-and notes that readers seek books similar to what they have already read to re-create a pleasurable experience. She urges librarians to consider "what it is about a book that draws us in, rather than what the book is about." Focusing on the context of reading for pleasure, Ross presents a model for the process of choosing a book which includes five related elements: reading experience wanted (reader's mood), alerting sources, elements of the book itself (e.g., subject, characters, setting), clues on the book itself (e.g., author, genre), and cost in time, money, or cognitive energy. ${ }^{9}$ On the other hand, Wyatt discusses the following eight appeals for nonfiction: pacing, characterization, story line, detail, learning and experiencing, language, setting, and tone. ${ }^{10}$ Wyatt also emphasizes the need for utilizing and presenting the myriad associations and themes existing in materials of multiple formats for providing RA and showcases how this can be visually represented in "reading maps."11 Forsyth also uses "appeal characteristic" to refer to what users enjoyed about various types of media objects such as books, films, or works of art. ${ }^{12}$

Research in media studies uses the term "gratifications" to describe uses pleasing to users in television and video game media, and the terms "motivation" and "motivators" are used in game studies to describe factors that appeal to or otherwise influence people to play video games. ${ }^{13}$ In this context, Malone states, "an activity is said to be intrinsically motivated if people engage in it 'for its own sake,' if they do not engage in the activity to receive some external reward such as money or status."14

Hunicke et al. put forth the MDA (Mechanics, Dynamics, and Aesthetics) framework as a formal explanation of appeals of video games. ${ }^{15}$ They explain "aesthetics" as "the desirable emotional responses evoked in the player, when she interacts with the game system," contrasting it with mechanics and dynamics, which concern the rules of the game or how mechanics are played out. ${ }^{16}$ They suggest a taxonomy of eight core aesthetic goals to explain why different games appeal to people: sensation, fantasy, narrative, challenge, fellowship, discovery, expression, and submission. ${ }^{17}$

On the basis of these definitions of "appeals" and related terms, we define appeals as "elements of media that draw people in by evoking certain emotional and intellectual experiences when a user interacts with the media."

\section{Prior Research on Appeals}

A substantial body of literature exists on appeals and gratifications of video games across a variety of disciplines. Taken together, these studies provide a great deal of insight into why people play video games. However, direct application of the appeals for video games identified in these studies for improving recommendation is limited for many reasons.

One reason is the scope of these studies. Earlier studies on appeals focused on investigating appeals of video games specifically for certain demographic groups, such as children, teens and young adults, or college and high school students. ${ }^{18}$ Malone identified the three strongest reasons children are attracted to games: challenge, fantasy, and curiosity; Selnow discusses multiple factors that motivate people to play: gameplay is preferable to human companions or teaches about people and provides companionship, activity or action, or solitude or escape. ${ }^{19} \mathrm{~A}$ survey by Wigand et al. determined that excitement, the satisfaction of doing well, and tension reduction were the three primary gratifications of arcade video game players. ${ }^{20}$ Many earlier studies were also limited to investigating users of specific types of games, such as arcade games or MMORPGs (Massively Multiplayer Online Role-Playing Games). ${ }^{21}$ In particular, Yee studied thirty thousand MMORPG players to explore their motivations, identifying factors such as achievement, relationship, immersion, escapism, and manipulation. ${ }^{22}$ Work in game design provides explanation of many appeals such as Hunicke et al.'s aesthetics, and Ellinger's nuanced subcategories of those appeals. ${ }^{23}$ 
However, these are based on the authors' intuitions and opinions rather than empirical user data.

Additionally, prior research regarding appeals often emerges from differing objectives rather than specific goals of recommendation. For instance, Malone was interested in how appeals can be adapted to formal education. ${ }^{24}$ Studies by Griffiths and Phillips et al. researched why people are attracted to video games to better understand game addiction. The appeals they identified were similar to those from previously discussed studies: arousal, social rewards, skill testing, displacement, stress reduction, passing time, avoiding things, and cheering oneself up. ${ }^{25}$ Choi and Kim were interested in discovering design factors based on the reasons why people play online games to increase customer loyalty. ${ }^{26}$ Other studies correlate appeals, gratifications, motivations, and personality types with other variables; for instance, to predict game preferences and the amount of game use, examine gender differences, or predict player frustration. ${ }^{27}$ Only a single study explored appeals of video games for RA in libraries; however, it focused on exploring how Pearl's four doorways could be linked to specific video game characteristics rather than identifying new appeals. ${ }^{28}$

In contrast, our work aims to support recommendation for all library users by drawing on empirical data from a larger and more diverse user group to derive a broader understanding of appeals for general users, rather than certain demographics. Our goal is specifically to identify appeals from users' descriptions and understanding of games and understand the relationship between these appeals and existing genres. Our objective is improving the quality of advisory services and supporting video game information retrieval systems that can be used for RA service and other purposes from a user-centered perspective.

\section{METHOD AND DESIGN}

We conducted a large-scale survey to identify people's appeals for contemporary video games. The full survey was conducted as part of a larger research agenda, and included twenty-eight questions on aspects of video-game-playing experience, game-related information seeking, and game collecting and organization behavior. The full questionnaire and detailed information about survey deployment can be found in Lee, Clarke, and Kim. ${ }^{29}$ Survey invitations were distributed through game-related physical and online venues including the Seattle Interactive Media Museum video game exhibition, game-related forums, various university mailing lists, as well as researchers' social media networks. A total of 2,163 respondents participated in the survey; of those, 1,257 completed the survey.

Here we present findings from the survey specifically regarding appeals and their correlations with existing genres. First, from survey question 4 (Q4) we identified appeals of video games from responses to an open-ended question about people's favorite games and why they appealed to them. The responses were coded by two independent coders through an iterative process, following the consensus model. ${ }^{30}$ The initial codebook contained codes identified from previous research on appeals of video games. After completing the independent coding process with the initial codebook, coders met and discussed codes that needed to be revised, added, and removed after looking at the user data. Coders then independently reviewed and revised their coding using the revised codebook. After the second round of coding, coders discussed the cases where disagreement occurred, aiming to reach consensus. The first author acted as an arbiter when consensus could not be reached.

Second, we focused on core reasons people play specific genres of games (Q6, Q7). Respondents were asked to select their favorite genre from a list of eleven common video game genres. They were then asked to identify all the reasons why that genre appealed to them from a list of twelve appeals written in simple sentences (e.g., "Competition: I like competing against other people"). These answer choices were drawn from the most commonly used appeals identified in existing literature. Descriptive statistics were derived from the responses to quantitative questions (Q6, Q7).

\section{DISCUSSION OF APPEALS}

From responses to the open-ended question asking reasons for liking their favorite video games, we identified the following sixteen appeals representing core reasons why players are attracted to and play certain video games (table 1).

\section{Narrative}

Narrative was the most commonly identified appeal for video games. A vast majority of respondents stated that experiencing some kind of story was a major reason they selected and/or enjoyed their favorite games, and had a longer lasting appeal over time (e.g., respondent 831 (R831) said, "I play a wide variety of games, but the ones that stick with me the most are the ones whose story burns itself into my memory").

According to many responses, for a narrative to be appealing, it needed not only a good story, but supportive and integrated gameplay and mechanics, and relatable characters. Narrative was frequently mentioned in conjunction with gameplay (e.g., "I prefer games that have a narrative component that is creatively manifest through gameplay" (R1047)). Although players preferred when narrative and gameplay components worked together, many admitted preferring storyline over gameplay, even to the point where narrative overcame functional faults in a game ("KOTOR2 was unfinished and buggy, but I was very invested in the story of Kreia, one of the game's major characters" (R322)). This suggests that metadata describing the centrality of narrative to the game could be useful.

Engaging and relatable characters were key to a game's narrative appeal. Many participants became involved with 


\section{FEATURE}

Table 1. Appeals Identified from Survey Data

\begin{tabular}{|c|c|c|}
\hline Appeal & Definition: When the Core Reason for Playing a Games is to ... & Frequency \\
\hline Narrative & Experience and appreciate the story & 628 \\
\hline Challenge & Feel the joy of overcoming obstacles or challenges & 292 \\
\hline Sensation & Appreciate the visual and/or auditory content /Enjoy the physical stimulation & 287 \\
\hline Fellowship & Enjoy the company of others & 215 \\
\hline Nostalgia & Revisit or rethink a past experience & 183 \\
\hline Fantasy & Immerse oneself in a fantasy world, and do things not possible in real life & 176 \\
\hline Exploration & Explore and/or discover something new & 173 \\
\hline Mood & Experience and/or appreciate a particular emotion & 162 \\
\hline Depth & Appreciate the scale and choices/consequences & 136 \\
\hline Creativity/Innovation & Appreciate its innovative, novel, or experimental aspects & 102 \\
\hline Expression & Express oneself and/or create things in the game world & 101 \\
\hline Accomplishment & $\begin{array}{l}\text { Feel the satisfaction of achieving, acquiring and/or accomplishing something, often motivated by } \\
\text { rewards or status, and/or completing all possible options }\end{array}$ & 66 \\
\hline Competition & Feel satisfaction of competing and/or winning against others & 62 \\
\hline Submission & Pass time and/or "turn off one's brain" and unwind/relax & 50 \\
\hline Mastery & Feel satisfaction from perfecting one's skills & 21 \\
\hline Learning & Learn something new & 14 \\
\hline
\end{tabular}

the characters, like previous studies regarding appeals of fiction. ${ }^{31}$ Pearl notes that readers may feel as if they had lost someone dear to them when a book ends because of a strong emotional connection with the characters. ${ }^{32}$ This was also evidenced in our data: "You become involved with the characters and their lives and care about the outcome" (R1204). Caring was often facilitated through relatability-characters with which players felt commonalities. Diversity and variety of characters allowed players more opportunities to relate: "Half life 2 had a fantastic story and well-rounded characters I really grew attached to" (R695). Detailed descriptions of characters' types and characteristics would help connect these users to the kinds of games that would be appealing to them. Identifying different character tropes used in games could also be helpful for people who want to see or avoid kinds of characters.

\section{Challenge}

Challenge was the second most mentioned appeal and one of the most commonly identified appeals in prior literature. ${ }^{33}$ Our data revealed multiple aspects of challenge. It may reflect physical aspects, such as being able to complete a game action in a short time or perfect manner. In other cases, challenge reflected intellectual aspects, requiring people to solve difficult problems, push boundaries, and challenge moral beliefs: "I like games that challenge me, either mechanically (Donkey Kong) or through story and setting (Catherine and Fallout 3). Catherine is the first truly "adult" game in my opinion, tackling issues like pregnancy and infidelity" (R34).
Opinions varied regarding the degree of challenge users found ideal. Some users sought very challenging games ("Hardcore experience. Play perfect or die...." (R13)) or easy pick-up and go games ("I can actually get somewhere with it because it's point and click ... It's very easy." (P1)). However, for others, getting just the right amount of challenge in a nonintimidating manner was important: not so hard that they got frustrated, but at the same time, not so easy that they got bored ("There [sic] are easy enough that I can win occasionally, but not so easy that I always win" (R141)). Games with a gentle learning curve were appreciated: "Game worlds open gradually, at a pace that corresponds to your mastery of using and accumulating simple tools and resources" (R334). Some appreciated games that offered varying difficulty levels ("I also liked how easy and difficult they could be and flex to the player" (R644)), just as Ross discussed how users seek materials with different levels of challenges (either based on novelty or plot complexity) depending on their current situation and mood. ${ }^{34}$ Exposure to new challenges or opportunities to apply different strategies to tackle a complicated problem was appreciated by some: "Monster Hunter tests every skill you've ever learned as a gamer and pushes them that much farther" (R475). In addition to identifying games good for challenging users, it may be helpful to describe what kinds of challenges are presented in a game, and also whether the game offers multiple difficulty levels.

\section{Sensation}

To understand sensory appeals in a more detailed manner, we coded responses for sensation with three separate 
aspects: auditory, physical, and visual. Visual sensation was mentioned the most at 192 times, followed by auditory (82), and physical (13).

To describe visual sensation, participants tended to use subjective terms such as "pretty," "beautiful," "aesthetic," "artistic," and "interesting." Some participants described the visual style of game environments ("Diablo II certainly gleaned a lot from it's [sic] environment and visuals" (R524)) while others specifically described the design of the characters ("Kirby Super Star has well designed characters, satisfying sound effects and wide selections of visually appealing abilities" (R935)).

Participants also emphasized the importance of music. Sound and music may not be the reasons that participants select certain video games, but they play an essential role in creating atmosphere and bringing back users' emotional state during the gameplay (e.g., "FF7: First RPG of any kind I ever played. The songs still give me chills, even have the official soundtrack" (R1018)).

In terms of physical sensation, most participants had comments on music-related games or sports games. Being physically active while playing was another appeal: "Dance Central because I like dancing, and find trying to compete with my own score in the game is intrinsically fun to the point that I forget that I am exercising" (R1210).

Sensation was often discussed in combination with different sensory appeals (e.g., "Short, beautiful game with gorgeous music" (R599)). Participants have multisensory experiences when playing video games, thus having only a good soundtrack or graphic design may not satisfy players. Players expect to experience an immersive feeling, and visual, auditory, and physical sensation need to work together to create this immersive environment. There may be a linguistic sensation combined with other sensory appeals as well, as Pearl described. ${ }^{35}$ It can be the lyrics of songs used in the game, how a character talks, or how the narration is done. Ermi and Mäyrä distinguished the sensory immersion related to audiovisual execution of games as the first dimension of a gameplay experience, along with challenge-based immersion and imaginative immersion. ${ }^{36}$ Digital games have evolved into "audiovisually impressive, three-dimensional and stereophonic worlds that surround their players in a very comprehensive manner." ${ }^{37}$ Large screens and powerful sounds that overpower the sensory information coming from the real word can cause players to become entirely focused on the game world and its stimuli. To represent these different aspects of sensation, it may be useful to have metadata regarding visual styles, types of user interactions, and soundtracks in catalogs or recommendation tools.

\section{Fellowship}

Fellowship appeals to gamers who spend a lot of time playing games as well as those who play games more casually. We identified two aspects of social playing: playing with friends and/or family and making friends through gaming. This aspect often dictated what kind of games people played. "The aspect of DOTA [Defense of the Ancients] and WoW [World of Warcraft] that have kept me playing is the teamwork. I like being able to play with my friends, especially those who are far away. With WoW, I've made some distant friends with whom I now meet up with (IRL!) every summer ... Rock Band I played with my husband, and it was just a fun way to blow off some steam and spend time together" (R390).

In addition to concurrently co-playing within the game or taking turns, another type of socializing occurred via spectating, where people watch each other play: "Even though Pikmin is single player we would take turns playing/watching" (R876). Also, competing with other people was another aspect that people enjoyed about playing games with others which we discuss in more detail in a later section.

Some respondents actively avoided or disliked playing together. Sometimes it had to do with the type of games they preferred (e.g., "logic-based, solitary (games)" (R360); "I like playing solo, and prefer killing aliens to killing people" (R987)). In other cases, they were more interested in game progress or success rather than competing with others, or did not want to rely on other players to progress in the game.

Our data indicates that enumerating different user interactions (e.g., co-op, couch co-op, online co-op, multiplayer, etc.) could be useful.

\section{Mood and Nostalgia}

Respondents also mentioned the important role of mood when describing their favorite games. Previous studies identify mood as one of the most frequent appeals related to multiple types of media. ${ }^{38}$ Saricks discussed tone and mood as part of her list of appeal elements, and Ross and Chelton emphasize the mood as the bedrock issue, a critical element for users when they choose fiction. ${ }^{39} \mathrm{Hu}$ and Lee, Hill, and Work, also highlight the importance of mood in users' music seeking and listening activities. ${ }^{40}$ Many described how video games can evoke powerful emotional reactions and leave a profound effect, something that is not typically obtained in daily life. "All of these games I have gotten amazing experiences out, happiness, sadness, anger, frustration, and love. They give me the experience I need at a time and are extremely great story tellers" (R568).

There were a small number of predominant moods mentioned frequently: humor and silliness, intense excitement, and horror and darkness. Other moods such as peacefulness, sadness, and anxiety were also mentioned, but rarely: "Spec ops is the odd one out, I did not enjoy myself while playing this game, as the game progressed I felt miserable, uncomfortable and sometimes even sick. It is a game that allows you an insight in your own reaction to the true horrors of war." (R595). Some participants also mentioned how games helped players during emotionally challenging times: "These 


\section{FEATURE}

games really shaped the person that I am today. They kept me happy during sad times, and left a huge impact in how I see the world" (R817).

Nostalgia was a feeling specifically mentioned by many participants. Nostalgia is the mood produced by appreciating objects, people, or experiences affiliated with a previous time. ${ }^{41}$ For many participants, some games embodied their past positive experience with family or friends and they played these games to relive those moments: "I grew up on LoZ [The Legend of Zelda] and FF [Final Fantasy] 8. When other kids were outside playing games or getting into the seedier parts of surviving the ghetto, Link and Squall were there to be protectors and role models. .. . Squall pointed out that there were only perspectives, and it was the basis for my desires of a profession in psychology" (R510).

Using nostalgia as an access point for recommendations may be difficult because it is very personal; however, discovering games that share similar characteristics with games players feel nostalgic toward may be desirable. Being able to find games that tend to evoke certain moods would also be appreciated.

\section{Fantasy}

Two main keywords related to the appeal fantasy that emerged were "immersive" and "escapism." RPG (role-playing game) was a frequently mentioned genre when participants described enjoying immersive adventures. Generally, RPGs include a fantastical setting with elaborate storylines featuring many characters and a wider variety of sounds. These aspects help game players enjoy an interactive cinematic experience. "I love the immersiveness of an RPG. Zelda and the Elder Scrolls (and WoW, to a lesser extent) made me really feel like I, personally, was there in the game world, being magical and having wild adventures. It was a total escape from reality" (R390). "I also like having skills in video games that I'm lacking in real world" (R175).

Escapism has been discussed in previous studies as one of the main appeals in media consumption. Vorderer, Klimmt, and Ritterfeld claimed that media consumers desire to escape their social world, particularly those who live substantially underprivileged lives. ${ }^{42}$ Similarly, Usherwood and Toyne found that imaginative literature helped readers escape their day-to-day experiences and the pressures of life. ${ }^{43}$ Our findings align with these studies, as some of our participants played video games to escape from the tough realities they experienced: "Many of these games I played during my teenage years when I most needed an escape from stress and anxiety" (R1637).

Some participants mentioned enjoying opportunities to do things in games not usually possible in real life, from saving the world to committing crimes: "I enjoy roleplaying as a liberal socialist democracy liberating the global working class from exploitative monarchs and fundamentalists" (R666); "You can do things in them you can't do in real life (or at least not without getting arrested)" (R164).

\section{Exploration and Depth}

Exploration and depth represent two facets of discovery, requiring effort from players to uncover, engage, and understand locations or systems. Exploration addresses the need or option for players to discover new locations, characters, and other components of the game world. Depth addresses the number and types of interactions and gameplay elements present within the game.

One of the four player types in Bartle's widely used video game player typology is "explorer," underscoring the importance of this appeal. ${ }^{44}$ In addition to "explore" and "exploration," other terms used to express this sentiment included "discovery," "expansive," and "wide," to describe the volume of places and things to explore. A significant portion of the responses also referred to the "world" of the game, indicating that exploration is linked to setting: "They all had really rich worlds for me to explore and learn about that made playing the game so much more interesting for me" (R496).

While exploration is closely related to environments, survey responses underscore the nature of exploration as an active process and an affordance of games. Pearl, Saricks, Warner, and Mediatore discuss setting as the backdrop for books, film, and audiobooks. ${ }^{45}$ However, the term exploration as used by survey respondents implies an active, playercontrolled process. Additionally, players mention exploration in the context of aspects of games other than setting. Ermi and Mäyrä describe exploration as a fundamental component of the gameplay experience. ${ }^{46}$ Similarly, Przybylski, Rigby, and Ryan describe exploration as an affordance to a player granted by the ability to control what occurs onscreen.$^{47}$ Hunicke et al. do not use the term "exploration" to describe this process, but outline the appeal of discovery, or "game as uncharted territory," implying exploration. ${ }^{48}$ Such articulations of this concept of affordance in literature highlights the importance of choice. Our user data support the argument that affordances and choice in games help serve the appeals of discovery, exploration, and depth, a structure that is unique to video games.

References to depth in participant responses reflected player agency and options. Players appreciated when a game's structure allowed the story to be altered based on player action and other player-initiated events. Key terms used by participants include "agency," "choice," "decisions," "consequences," and "non-linear": "Otherwise having a lot of player agency in the world the games is set in (RPGs)." (R723); "They allow me to make my own choices, if I fail or everything goes wrong it's because of previous choices made" (R841).

Przybylski, Rigby, and Ryan described this type of choice as autonomy, "flexibility over movement and strategies, choice over tasks and goals," and link the level of this choice to the design of the game. ${ }^{49}$ They applied the concept of SDT (self-determination theory) to video games, concluding that autonomy and choice are predictors of game enjoyment and continued play. One way to represent this information in catalogs or recommendation systems may be to specify if a 
game offers multiple versions of the story or game events. Additionally, responses about the depth of a game were tied to the affordances of the game world (e.g., how "open" the game world was), where players are free to explore the world in their own way, in parallel with witnessing the consequences of their decisions in the game world. Participants' concept of depth also encompasses the number and variety of mechanical and strategic options available to players (e.g., types of game mechanics, such as puzzle and combat, and types of systems in a game, such as social systems and abstract systems).

\section{Expression and Creativity/Innovation}

While many players learn about themselves through game interactions, survey responses indicate that expression as an appeal is less about opportunities to understand oneself and more about chances to use the game to demonstrate personality and creative ideas. One easy way for players to express themselves is through customization options: the ability to change or modify aspects of a game such as characters. Customization is not limited to visual similarities. Some games allow players to customize experiences within in the game: "[It] lets you be whomever[sic] you want. In my case, I be myself. I'm a medical student, with a particular interest in computers and also happen to be a persuasive individual. And I do not like killing people, at all. I can skip past people without killing anyone, persuade them, only if necessary, dispatching them" (R720).

Games that let players roam freely with no set course of action ("open world," "sandbox," or "free-roaming" games) move beyond customizations. These games offer players more freedom by letting them create game experiences themselves: "Minecraft is a place that I can truly express myself in my very own way, possibilities are endless, and so are the lego pieces" (R720).

Games that offer these high levels of freedom allow for and inspire creativity. Players enjoy the ability to create characters, buildings, cities, even worlds. Such opportunities appeal so strongly that many enjoy the creative aspects more than actually playing the game: "I can do without the warring aspects, I just like to create" (R140).

Freedom and the ability to feel in control of a video game enable self-expression. The ability to make choicesfrom changing an avatar's hair to creating an entirely new narrative-powers a game's ability to let players express themselves. Thus, games offering the ability to customize are likely to interest players motivated by this appeal. To provide access to games for self-expression, we need metadata that identify customization options. Perhaps an "open world" genre or other specific functions or mechanics can be identified, distilled, and subsequently described and applied to games.

Another appeal relevant to expression that emerged from the responses was creativity/innovation. Some participants were attracted to games because of novel, innovative, and experimental aspects of game design, including mechanics, visual style, or narrative: "They take risks with their genres and expand them in new ways" (R170); "These games all presented either a new way/style of gaming that set a precedent for future games in the genre" (R470).

\section{Accomplishment, Learning, and Mastery}

Accomplishment, learning, and mastery are related by a theme of goal achievement. Yet closer analysis reveals different types of goals, methods of achievement, and attractions on the basis of intrinsic, content-based elements versus extrinsic, personal responses. Delineating between these differences offers a nuanced understanding of how goal-based appeals motivate users as well as implications for how they might be used for recommending games.

The most straightforward goal-based appeal is accomplishment, or achievement for achievement's sake. Accomplishment manifests as the accumulation of points to receive a reward within a game, such as a new level, feature, or higher leaderboard position. The appeal in these cases is the achievement of status. It may be simply for personal achievement (e.g., "II] gain a sense of fulfillment when [I] "level up" (R729)). Status may also be competitive in conjunction with others. Although not universal, accomplishment often includes aspects of instant gratification: not only do users want to earn points and move levels, they want to do it quickly and reap the rewards immediately.

Learning is both experiential and content-based. Some participants expressed interest in games that supported and fostered their knowledge even though those games were not originally designed for educational purposes, such as learning English (R595), history (R567), and physics (R411). "The way it teaches you orbital mechanics on the fly (which isn't a simple concept by any means), gives you intuitive knowledge of rotating reference frames (aced Physics 1, thanks Squad)" (R411).

Educational organizations like libraries and schools increasingly seek ways to foster learning via games. For printed materials, Wyatt noted that "learning and experiencing" was an important factor, especially for nonfiction, where authors often intend to provide a "teachable moment" to readers. ${ }^{50}$ However, because educational experiences are based on the knowledge and experiences each player brings to a game, it is impossible to know which games will enable educational experiences for each user. Educators rely on content within games, which may or may not be appealing to players. Reliance on educational content as a motivational factor is unlikely to attract those for whom educational experience appeals.

Mastery is not educational, but rather related to perfecting one's skills. While education may contribute, mastery is most commonly achieved through repetition or practice. Skills may be physical interactions, such as Tetris forcing one participant to improve hand-eye coordination (R370). Another enjoyed sharpening rhythmic skills and reflexes 
Table 2. Relationship between Appeals and Genres

\begin{tabular}{|c|c|c|c|c|c|c|c|c|c|c|c|}
\hline & $\begin{array}{l}\frac{7}{2} \\
\frac{7}{2}\end{array}$ & 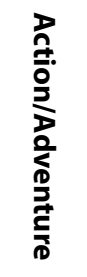 & 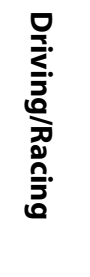 & $\begin{array}{l}\text { 꼼 } \\
\frac{0}{5} \\
\overline{5}\end{array}$ & 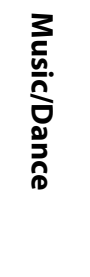 & $\begin{array}{l}\text { D } \\
\frac{N}{D}\end{array}$ & गु & 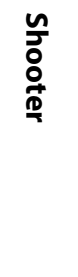 & $\begin{array}{l}\frac{n}{3} \\
\frac{5}{2} \\
\frac{0}{0} \\
\frac{0}{3}\end{array}$ & $\frac{n}{\frac{0}{7}}$ & 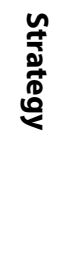 \\
\hline Aesthetics & 50.0 & 71.5 & 33.3 & 41.7 & 7.1 & 17.6 & 58.4 & 47.1 & 28.6 & 19.0 & 33.7 \\
\hline Physical Interaction & 6.3 & 5.5 & 16.7 & 8.3 & 64.3 & 4.4 & 0.9 & 0.8 & 3.6 & 19.0 & 1.1 \\
\hline Fantasy & 42.5 & 74.0 & 25.0 & 33.3 & 7.1 & 13.2 & 75.2 & 52.1 & 50.0 & 19.0 & 42.1 \\
\hline Narrative & 33.8 & 84.5 & 16.7 & 50.0 & 7.1 & 13.2 & 89.0 & 55.5 & 28.6 & 19.0 & 55.8 \\
\hline Challenge & 55.0 & 58.0 & 33.3 & 75.0 & 35.7 & 65.9 & 46.1 & 58.8 & 53.6 & 38.1 & 76.8 \\
\hline Fellowship & 38.8 & 20.0 & 66.7 & 50.0 & 57.1 & 22.0 & 22.3 & 58.8 & 21.4 & 47.6 & 53.7 \\
\hline Competition & 17.5 & 4.5 & 41.7 & 75.0 & 21.4 & 13.2 & 9.1 & 49.6 & 28.6 & 38.1 & 45.3 \\
\hline Exploration & 50.0 & 87.0 & 16.7 & 8.3 & 7.1 & 12.1 & 79.8 & 44.5 & 53.6 & 9.5 & 35.8 \\
\hline Expression & 12.5 & 15.5 & 8.3 & 25.0 & 7.1 & 2.2 & 46.3 & 18.5 & 57.1 & 4.8 & 17.9 \\
\hline Submission & 43.8 & 32.5 & 8.3 & 41.7 & 28.6 & 73.6 & 33.5 & 42.0 & 60.7 & 42.9 & 40.0 \\
\hline Accomplishment & 31.3 & 29.5 & 25.0 & 50.0 & 42.9 & 27.5 & 35.0 & 33.6 & 25.0 & 19.0 & 29.5 \\
\hline Mastery & 27.5 & 32.5 & 8.3 & 75.0 & 42.9 & 42.9 & 30.1 & 49.6 & 35.7 & 14.3 & 61.1 \\
\hline Peer pressure & 6.3 & 5.5 & 0.0 & 8.3 & 0.0 & 7.7 & 8.7 & 22.7 & 7.1 & 23.8 & 18.9 \\
\hline Nostalgia & 46.3 & 30.0 & 25.0 & 41.7 & 7.1 & 20.9 & 22.3 & 12.6 & 32.1 & 19.0 & 20.0 \\
\hline Total Responses for Genre & 80 & 200 & 12 & 12 & 14 & 91 & 529 & 119 & 28 & 21 & 95 \\
\hline
\end{tabular}

by playing musical games like Guitar Hero and Rock Band (R416). Skills may also be strategic, such as repeated attempts to defeat a game using different approaches. Unlike accomplishment, mastery is about slow, deliberate, progression: "[I like] any game that requires study and practice of a skill. Anything very challenging where you are able to make slow but steady progress. Games where you are forced to learn and practice to improve. Being rewarded with progression from hard work" (R763).

\section{Competition}

Competition appeals to players who enjoy striving to exceed existing gaming performances. While most participants who described competitive appeals mentioned others, on some occasions participants described competing against themselves, for instance, to beat a previous high score: "competitive (either against friends, the computer, or myself)" (R914); "competitive either through multiplayer or against high scores" (R763).

Unlike accomplishment, which reflects the enjoyment of winning, competition is more than enjoyment derived from victory. While competition inspires players to hone their skills, performing well is not the sole motivation (see "Accomplishment, Learning, and Mastery" above). Competition includes these aspects as well as comparison with and demonstration of such prowess to others: "I began playing online and got a rush from fighting other players close to my skill level. I still suck, but that feeling I get when the match gets close keeps me coming back" (R9).

Competitive games allow players to not only improve their skills, but also to test their abilities against others to see how far they have advanced. Competitive skill displays reflect pride in one's ability, such as "bragging rights" (R447) and satisfaction in subjugating others: "Gran Turismo was a great game for putting the beat down on my siblings. They could get higher scores than me in Mario but, by God, I was going to make them eat dust in GT" (R1235).

Like other appeals, competition reflects a continuum of interaction. Some respondents specifically preferred games without competitive components: "I like games that don't put me in direct competition with other people. So I usually gravitate toward games that I play solo \& concentrate on puzzle skills or my own accomplishments" (R740). Others enjoyed competition that involved aspects of cooperation: "[I like] League of Legends for the hard competition and required teamplay, not unlike a sports match" (R366).

Except for playing against oneself, competition involves others, be it other players present in the space, other players connected online, or computer intelligence. This, combined with the spectrum of coverage, means that the appeal of competition is likely to co-exist with the appeal of fellowship. 
Table 3. Top Three Appeals for Each Genre

\begin{tabular}{|c|c|c|c|}
\hline Genre & First-Ranked Appeal & Second-Ranked Appeal & Third-Ranked Appeal \\
\hline Action & Challenge & $\begin{array}{l}\text { Aesthetics } \\
\text { Exploration }\end{array}$ & \\
\hline Action/Adventure & Exploration & Narrative & Fantasy \\
\hline Driving/Racing & Fellowship & Competition & $\begin{array}{l}\text { Aesthetics } \\
\text { Challenge }\end{array}$ \\
\hline Fighting & $\begin{array}{l}\text { Challenge } \\
\text { Competition } \\
\text { Mastery }\end{array}$ & & \\
\hline Music/Dance & Physical interaction & Fellowship & $\begin{array}{l}\text { Accomplishment } \\
\text { Mastery }\end{array}$ \\
\hline Puzzle & Submission & Challenge & Mastery \\
\hline RPG & Narrative & Exploration & Fantasy \\
\hline Shooter & $\begin{array}{l}\text { Challenge } \\
\text { Fellowship }\end{array}$ & Narrative & Fantasy \\
\hline Simulation & Submission & Expression & $\begin{array}{l}\text { Challenge } \\
\text { Exploration }\end{array}$ \\
\hline Sports & Fellowship & Submission & Challenge \\
\hline Strategy & Challenge & Mastery & Narrative \\
\hline
\end{tabular}

\section{Submission}

Submission is an appeal derived from the desire to unwind, relax, or simply pass the time. While Hunicke et al. and Schuurman, De Moore, and De Marez define submission as a passive pastime or time-killing function, we refine it here to capture the addition of purposeful disengagement expressed by participants. ${ }^{51}$ Views on mass media consumption reflect diverse perspectives of audiences as both active and passive participants. Our participants also reflected both perspectives. ${ }^{52}$ Participants who played games as "a way to pass the time for a couple of minutes when I'm listening on my iTouch" (R423) captured basic aspects of submission. Additionally, many participants mentioned playing games to intentionally disengage from the world around them-a kind of mindless relaxation: "Ninja Mahjong and Plants vs. Zombies are good mindless games that keep you occupied after you've been reading all day and are too tired to think" (R670).

Although games used to fill short bursts of time must be quick and easy to play, the "mindless" quality of a game is not necessarily intrinsic. Just because games were used to "turn off one's brain" does not mean the games themselves were simple or uncomplicated. Almost all game genres were identified by survey respondents as being played to unwind and relax, including RPGs, action and adventure games, shooters, and puzzle games. At first, this seems incongruous - many of these genres require focus and concentration, yet people play them for "mindless" activity. Some of this ability arises from familiarity with the game. In other cases, participants were attracted to complex game interactions because they distracted players from other aspects of their lives: "Burnout revenge is a game requiring so much focus that you can let everything else drift away" (R510). In these cases, gaming is comparable to activities like reading, playing music, dancing, and playing sports, where focus on the task at hand forces other thoughts away. Choice of game content among players seeking submission will vary, just as some people play basketball to take their mind off things while others prefer a good mystery novel. Since contextual experience varies among users, it is difficult to recommend games based on these "submissive" qualities.

\section{RELATIONSHIP BETWEEN APPEALS AND GENRES}

We explored the relationship between the preceding appeals and video game genres. While a substantial body of work exists on video game appeals for user groups (e.g., children, MMORPG players), none tried to identify which appeals are prominent for each genre using empirical user data. We looked at the correlation between respondents' appeals and their favorite and most familiar genres (table 2).

Table 2 shows the most commonly mentioned appeals for each genre are highlighted, with the three most commonly mentioned in bold. This shows noticeable differences in the most prominent appeal across genres. For instance, exploration is most important for action and adventure games; narrative for RPGs; and physical interaction for music and dance games. It also reveals previously unidentified similarities between certain genres. For instance, 


\section{FEATURE}

Table 4. Game Examples and Descriptions for Each Appeal

\begin{tabular}{|c|c|c|}
\hline Appeal & Relevant Terms and Phrases & Game Title and Description \\
\hline Narrative & $\begin{array}{l}\text { Good and compelling story; well- } \\
\text { developed characters; detailed } \\
\text { universe and lore }\end{array}$ & $\begin{array}{l}\text { Final Fantasy VI (Square, 1994): A role-playing game with an elaborate story featuring an } \\
\text { amnesiac woman with special powers who works with a large cast of characters with unique } \\
\text { abilities to challenge a mad warlord bent on world domination. } \\
\text { Persona } 5 \text { (Atlus, 2017): With a strong focus on its story, Persona } 5 \text { is about a group of high } \\
\text { school students who undertake adventures by using special powers that come from their } \\
\text { inner selves and transform them into Phantom Thieves. }\end{array}$ \\
\hline Challenge & $\begin{array}{l}\text { Difficult; requires skill } \\
\text { development; steep learning curve }\end{array}$ & $\begin{array}{l}\text { Ninja Gaiden (Xbox, 2004): An intricate and challenging action game where an accomplished } \\
\text { ninja must recover a stolen sword and avenge his clan. The game is filled with difficult } \\
\text { maneuvers, fights, and other challenges frequently requiring many attempts to complete. } \\
\text { Dark Souls (Fromsoft, 2011): An action role-playing game where the players take the role } \\
\text { of an undead asylum patient who must fulfill a prophecy. The game is combat-heavy and } \\
\text { features a detailed and complex system of fighting and many combat challenges. }\end{array}$ \\
\hline Sensation & $\begin{array}{l}\text { Beautiful; great aesthetics; art } \\
\text { games; games that require body } \\
\text { movement or rhythm; game with } \\
\text { good music }\end{array}$ & $\begin{array}{l}\text { Dance Dance Revolution A (Konami, 2016): A dancing rhythm game that requires players to } \\
\text { move in time with the music to complete dance routines for popular songs. } \\
\text { Flower (Thatgamecompany, 2009): Players control the wind to blow flower petals through } \\
\text { the air, which interacts with the rich game environment, causing flowers to bloom, plants to } \\
\text { grow, and environmental features such as windmills to activate. A rich musical score responds } \\
\text { to cues and events in the game. }\end{array}$ \\
\hline Fellowship & $\begin{array}{l}\text { Great to play with friends or } \\
\text { family; co-operative modes; } \\
\text { working together; teamwork; team } \\
\text { play; bonding with others through } \\
\text { playing }\end{array}$ & $\begin{array}{l}\text { Mario Kart } 8 \text { (Nintendo, 2014): A popular racing game where players take control of kart } \\
\text { racing characters from the Nintendo universe. The game features competitive multiplayer } \\
\text { tracks and battle challenges, playable with many players locally or online. } \\
\text { Overwatch (Blizzard, 2016) A team-based first-person-shooter action game, where players } \\
\text { work as a team to defeat rivals in combat arenas. }\end{array}$ \\
\hline Nostalgia & $\begin{array}{l}\text { Nostalgic; remastered games; } \\
\text { reminds you of your childhood; } \\
\text { old school; "retro" }\end{array}$ & $\begin{array}{l}\text { The Legend of Zelda (Nintendo, 1986): A classic adventure game featuring the renowned } \\
\text { character Link, who explores the world of Hyrule to collect pieces of the legendary "Triforce" } \\
\text { artifact to defeat a villain and rescue the princess Zelda. } \\
\text { Cave Story (Studio Pixel, 2004): A side scrolling adventure game with the player taking the } \\
\text { role of an explorer who seeks to protect the inhabitants of a large cave from a would-be } \\
\text { conqueror. The game is designed with a retro pixel art style and mechanics reminiscent of the } \\
\text { 8-bit console-game area. The game has been ported to several platforms since } 2004 \text {. }\end{array}$ \\
\hline Fantasy & $\begin{array}{l}\text { Escaping to another world; doing } \\
\text { something you cannot do in } \\
\text { real life; supernatural; mythical; } \\
\text { magical }\end{array}$ & $\begin{array}{l}\text { The Elder Scrolls IV: Oblivion (Bethesda, 2006): A player in a fantasy world must fight against } \\
\text { a cult intent on opening portals to the demonic world of Oblivion. The game features a rich } \\
\text { and well-developed world, history and lore extending back into other titles in the series, and } \\
\text { fantastic characters, places, and abilities. } \\
\text { Dragon Age: Origins (BioWare, 2009): A warden of the land must work with knights, wizards, } \\
\text { elves, and dwarves, and other fantastic personalities to turn back the tide of a demonic blight. } \\
\text { The game is set in the world of Ferelden, which has such fantasy elements as dragons, magic, } \\
\text { and parallel dimensions. }\end{array}$ \\
\hline Exploration & $\begin{array}{l}\text { Rich and expansive world to } \\
\text { explore; open-world; sandbox; } \\
\text { nonlinear plot; free to explore } \\
\text { anywhere }\end{array}$ & $\begin{array}{l}\text { Grand Theft Auto V (Rockstar North, 2013): An action game set in a contemporary world, } \\
\text { with the major mechanics and story of the game revolving around players stealing cars, } \\
\text { engaging in fights, and exploring expansive city environments and locations. } \\
\text { Etrian Odyssey II: Heroes of Lagaard (Atlus, 2008): A team of characters must explore an } \\
\text { elaborate labyrinth carved into the trunk of a massive tree to ascend to the castle above. }\end{array}$ \\
\hline Depth & $\begin{array}{l}\text { Deep and complex plot or } \\
\text { mechanics; game actions matter; } \\
\text { many choices }\end{array}$ & $\begin{array}{l}\text { Homeworld } 2 \text { (Relic, 2003): A simulation game set in deep space, where players control a } \\
\text { complex armada of spacecraft of many types, with many weapons and abilities, to win grand } \\
\text { battles using complex maneuvers and strategy in three-dimensional space. } \\
\text { Ogre Battle 64: Person of Lordly Caliber (Atlus, 2000): A complex strategy and role-playing } \\
\text { game set in a fantasy kingdom beset by civil war. The game features many mechanics, } \\
\text { character types, maps, and an elaborate branching storyline and plot that changes on the } \\
\text { basis of player actions. }\end{array}$ \\
\hline $\begin{array}{l}\text { Creativity/ } \\
\text { Innovation }\end{array}$ & $\begin{array}{l}\text { Innovative; creative; unique; } \\
\text { unusual gameplay; new kind of } \\
\text { game; games that define a genre }\end{array}$ & $\begin{array}{l}\text { Portal } 2 \text { (Valve, 2011): A unique action puzzle game where players employ a portal-creating } \\
\text { device to solve problems and work their way through a twisted laboratory filled with three- } \\
\text { dimensional puzzle challenges. } \\
\text { The Stanley Parable (Galactic Café, 2013): A first-person exploration game where players take } \\
\text { the role of Stanley, working their way through a surreal version of the modern world where } \\
\text { the story unfolds on the basis of immediate player behaviors and choices in unexpected ways. }\end{array}$ \\
\hline
\end{tabular}


Table 4. Game Examples and Descriptions for Each Appeal (cont.)

\begin{tabular}{|c|c|c|}
\hline Appeal & Relevant Terms and Phrases & Game Title and Description \\
\hline Expression & $\begin{array}{l}\text { Build or create anything you } \\
\text { want; share your creation; express } \\
\text { yourself }\end{array}$ & $\begin{array}{l}\text { Minecraft (Mojang, 2011): Players take the role of a character in an open world built with } \\
\text { blocks, representing different type of materials and resources. Players can use resources to } \\
\text { create new materials, items, and structures in the game. } \\
\text { Super Mario Maker (Nintendo, 2015): Players make and play levels using a toolbox containing } \\
\text { elements of the Super Mario Brothers series, from the original Mario Bros. to modern versions. }\end{array}$ \\
\hline Accomplishment & $\begin{array}{l}\text { significant time investment to } \\
\text { complete; many badges/trophies/ } \\
\text { achievements; completionism in } \\
\text { tasks or in-game set collecting }\end{array}$ & $\begin{array}{l}\text { World of Warcraft (Blizzard, 2004): A massively multiplayer online role playing game that } \\
\text { features thousands of hours of gameplay and hundreds of accomplishments and achievements } \\
\text { that can be pursued. } \\
\text { Pokémon GO (Niantic, 2016): An augmented-reality game where players collect fictional } \\
\text { creatures, train them, and use them to fight other players' Pokémon. There is an emphasis } \\
\text { on achieving high level advancement, completing higher tiers of badges and achievements, } \\
\text { finding rare Pokémon with strong abilities, and "catching them all." }\end{array}$ \\
\hline Competition & $\begin{array}{l}\text { Great for competing against each } \\
\text { other; e-sport; testing the skills }\end{array}$ & $\begin{array}{l}\text { Starcraft (Blizzard, 1998): A real time strategy game where players take control of the } \\
\text { operation of an army of spacefaring beings, and battles other players' armies in bouts. } \\
\text { League of Legends (Riot, 2009): A multiuser online battle arena game where players cooperate } \\
\text { with others and work together as a mixed battle team of fantastic champions in order to } \\
\text { defeat an opposing team. The game is played in set bouts. }\end{array}$ \\
\hline Submission & $\begin{array}{l}\text { Turn your brain off; unwind; relax; } \\
\text { forget about other things; simple } \\
\text { mechanics }\end{array}$ & $\begin{array}{l}\text { Abzû }(505,2016) \text { : A simulation game where players take the role of a scuba diver restoring } \\
\text { life to the ocean by visiting mystic springs. The game features relaxing underwater scenes, } \\
\text { music, and no challenges beyond open exploration of a mystical undersea environment. } \\
\text { Pokémon: Magikarp Jump (Select Button, 2017): A simple mobile game where players take } \\
\text { the role of a trainer of the Pokémon Magikarp and use them in jumping contests. The game } \\
\text { features a few very simple mechanics that are utilized repeatedly to advance through a linear } \\
\text { set of game challenges. }\end{array}$ \\
\hline Mastery & $\begin{array}{l}\text { Perfect your skills; memorize the } \\
\text { moves; get the perfect score; easy } \\
\text { to learn but hard to master }\end{array}$ & $\begin{array}{l}\text { Street Fighter IV (Dimps, Capcom, 2008): A fighting game where players take the role of } \\
\text { master martial arts fighters from around the world and compete in bouts. The game features a } \\
\text { very long learning curve, with opportunity for skill perfection lasting years. } \\
\text { Guitar Hero III: Legends of Rock (Neversoft, 2007): A rhythm game played via a special guitar } \\
\text { input where players match complex rhythms on screen to the buttons on the guitar. The } \\
\text { basic principles of play are easy to pick up, but songs become increasingly complex and some } \\
\text { require significant practice to master. }\end{array}$ \\
\hline Learning & $\begin{array}{l}\text { Learn about a topic; teachable } \\
\text { moment; use it for learning } \\
\text { languages; educational games; } \\
\text { significant tangential learning }\end{array}$ & $\begin{array}{l}\text { The Oregon Trail (MECC, 1971): A classic simulation game, with the aim of teaching children } \\
\text { about the nineteenth-century pioneer life. Players take the role of a family traveling by } \\
\text { covered wagon from Independence, Missouri, to the Oregon territory in the mid-nineteenth } \\
\text { century. } \\
\text { Civilization IV (Firaxis, 2005) A turn-based strategy game in a classic series where players } \\
\text { take the role of a historic figure leading and developing their nation from the beginning } \\
\text { of civilization to the advent of interstellar space travel. Players learn how to construct a } \\
\text { civilization with limited resources and develop international relations. }\end{array}$ \\
\hline
\end{tabular}

social aspects were important for shooter, sports games, and driving and racing games, evidenced by the high proportion of fellowship. Different combinations of appeals were also important for each of these genres. Looking at the top three appeals for each genre shows the differences more clearly (table 3).

The difference between the genres highly ranking "fellowship" was that, for shooter games, "challenge" was the second most important appeal, as opposed to "competition" for driving and racing games and "submission" for sports games. While fighting games may seem thematically closer to sports or driving and racing games, we see that "mastery" is the distinctive appeal for fighting games, but not for the other genres. Another similarity observed between strategy and action genres was the strong appeal of "challenge."
While "challenge" is also important for genres like fighting or shooter, it is more important than other appeals for strategy games. Puzzle and simulation games also shared a common appeal of "submission" even though they may not seem like similar genres. However, "expression" and "exploration" were also important for simulation games whereas "challenge" was more important for puzzle games.

The similarities and differences in the patterns of appeals observed between these different genres indicate the potential value of appeals as a complementary access point for searching and discovering games. Clearly, appeals represent a different dimension of information regarding why people choose to play certain games beyond existing metadata elements like genre and platform. Utilizing data on appeals of individual games could allow for collocation of different 


\section{FEATURE}

kinds of games, resulting in a more interesting and diversified set of recommendations across multiple genres.

\section{CONCLUSION AND FUTURE WORK}

We discussed sixteen user appeals for video games and how they correlate to video game genres. Users were drawn to games for a range of reasons, some closely related to the content (e.g., narrative and depth) and others related more to user experience (e.g., fantasy, mood). Some appeals were closely related (e.g., accomplishment, learning, and mastery; expression and creativity/innovation) and perhaps could be explained together under a broader appeal concept. Investigating the relationship between game genres and appeals showed interesting similarities and differences between genres that are not apparent from their themes and game mechanics.

We envision using these appeals as an additional access point for games in catalogs and other organizational systems to help improve user recommendations and RA for video games. Identifying and indexing the top appeals for games via crowdsourcing might be one approach. Displaying the proportion of appeals for each game (e.g., 60 percent narrative, 20 percent exploration, 10 percent fantasy, and 10 percent fellowship) from statistics of crowdsourced opinions might be another. Adding various metadata elements that explain different aspects related to these appeals, such as character types for narrative, visual style for sensation, or customization options for expression, is another possibility. In table 4 , we provide some terms and phrases that can be useful for more fully describing video games to users, reflecting on the appeals identified in this study. We also provide some sample game titles and short descriptions that are representative examples for each of the appeals.

Our ongoing work seeks to investigate these individual appeals further, specifically mood and narrative, focusing on their manifestation in other media. We want to understand whether, for example, mood appeals for video games are similar to or different from moods for music or film. Such understanding will help reach a larger goal of identifying cross-media appeals that can be used for recommendations across a wider variety of cultural objects. This will contribute to an existing larger movement in the field to "wholecollection RA" as proposed by Saricks, Trott and Williamson, and Wyatt, which aims to provide advisory services to the whole library collection including audiobooks, music, film, television series, and more..$^{53}$ As the amount of video games in libraries increases, they need to be considered part of the whole library collection.

\section{References}

1. Juris Dilevko and Candice F. C. Magowan, Readers' Advisory Service in North American Public Libraries (Jefferson, NC: McFarland, 2007).

2. Ibid.
3. Helen E. Haines, Living with Books: The Art of Book Selection (New York: Columbia University Press, 1950).

4. Meredith Schwartz and Henrietta Thornton-Verma, "The State of Readers' Advisory: Time, Lack of Training, and Shifting Staff Expertise Present Challenges, but Both High- and Low-Tech Tools Can Help to Deliver Better RA," Library Journal 139, no. 2 (2014): 30.

5. "Preferred Media Activities of U.S. Consumers in 2012, by Generation," Statista, 2017, http://www.statista.com/statis tics/281828/favorite-media-activities-in-the-us-by-age/.

6. Joyce G. Saricks, Readers' Advisory Service in the Public Library (Chicago: ALA Editions, 2005).

7. Saricks, Readers' Advisory Service, 40, 42; Joyce G. Saricks, The Readers' Advisory Guide to Genre Fiction, 2nd ed. (Chicago: ALA, 2009).

8. Nancy Pearl, "Check It Out with Nancy Pearl: Finding That Next Good Book," Publisher's Weekly 259, no. 12 (2012): 18-19.

9. Catherine Sheldrick Ross, "Finding without Seeking: The Information Encounter in the Context of Reading for Pleasure," Information Professing and Management 35, no. 6 (1999): 783-99.

10. Neal Wyatt, The Readers' Advisory Guide to Nonfiction (Chicago: ALA, 2007).

11. Neal Wyatt, "Reading Maps Remake RA," Library Journal 131, no. 18 (2006): 38-42

12. Ellen Forsyth, "From Assassins Creed 2 to The Five Greatest Warriors: Games and Reading," Australasian Public Libraries and Information Services 23, no. 3 (2010): 117-28.

13. Karl Erik Rosengren, "Uses and Gratifications: A Paradigm Outlined," in The Uses of Mass Communications: Current Perspectives on Gratifications Research, edited by Jay G. Blumler and Elihu Katz, 269-86 (Beverly Hills, CA: Sage, 1974); John L. Sherry et al., "Video Game Uses and Gratifications as Predictors of Use and Game Preference," in Playing Video Games: Motives, Responses, and Consequences, edited by Peter Vorderer and Jennings Bryant, 213-24 (Mahwah, NJ: Lawrence Erlbaum, 2006).

14. Thomas W. Malone, "Toward a Theory of Intrinsically Motivating Instruction," Cognitive Science 5, no. 4 (1981): 335.

15. Robert Hunicke, Marc LeBlanc, and Robert Zubek, "MDA: A Formal Approach to Game Design and Game Research," in Proceedings of the Challenges in Game AI Workshop, Nineteenth National Conference on Artificial Intelligence (2004): 1-5.

16. Ibid., 2 .

17. Ibid.

18. Malone, "Toward a Theory," 333-69; Gary W. Selnow, "Playing Videogames: The Electronic Friend," Journal of Communication 34 no. 2 (1984): 148-56; Rolf T. Wigand, Steven E. Borstelmann, and Franklin J. Boster, "Electronic Leisure: Video Game Usage and the Communication Climate of Video Arcades," Annals of the International Communication Association 9, no. 1 (1986): 275-93.

19. Malone, "Toward a Theory," 333-69; Selnow, "Playing Videogames," 148-56

20. Wigand, "Electronic Leisure," 275-93.

21. Selnow, "Playing Videogames," 148-56; Nick Yee, "The Demographics, Motivations, and Derived Experiences of Users of Massively Multi-User Online Graphical Environments," Presence: Teleoperators and Virtual Environments 15, no. 3 (2006): 309-29.

22. Yee, "The Demographics, Motivations, and Derived Experiences of Users," 309-29.

23. Hunicke et al., "MDA: A Formal Approach," 1-5; Benjamin Ellinger, "Engagement," Zen Rhino, accessed July 13, 2017, http://www.zenrhino.org/theory/engagement.

24. Malone, "Toward a Theory," 333-69.

25. Mark D. Griffiths, "Amusement Machine Playing in Childhood and Adolescence: A Comparative Analysis of Video Games and Fruit Machines," Journal of Adolescence 14, no. 1 (1991): 53-73; Carol A. Phillips et al., "Home Video Game Playing in 
Schoolchildren: A Study of Incidence and Patterns of Play," Journal of Adolescence 18, no. 6 (1995): 687-91.

26. Dongseong Choi and Jonwoo Kim, "Why People Continue to Play Online Games: In Search of Critical Design Factors to Increase Customer Loyalty to Online Contents," Cyberpsychology $\&$ Behavior: The Impact of the Internet, Multimedia and Virtual Reality on Behavior and Society 7, no. 1 (2004): 11-24.

27. Sherry et al., "Video Game Uses," 213-24; Diane Carr, "Contexts, Gaming Pleasures, and Gendered Preferences," Simulation \& Gaming 36, no. 4 (2005): 464-82; Bradley S. Greenberg et al., "Orientations to Video Games Among Gender and Age Groups," Simulation E Gaming 41, no. 2 (2008): 238-59; Alessandro R. Canossa, Anders Drachen, and Janus Rau Møller Sørensen, "Arrrgghh!!!—Blending Quantitative and Qualitative Methods to Detect Player Frustration," in Proceedings of the 6th International Conference on the Foundations of Digital Games, FDG 2011 (New York: ACM, 2011), 61-68.

28. Forsyth, "From Assassins Creed," 117-28; Pearl, "Check It Out," $18-19$.

29. Jin Ha Lee, Rachel Ivy Clarke, and Yea-Seul Kim, "Video Game Information Needs and Game Organization: Differences by Sex and Age," Information Research-An International Electronic Journal 20, no. 3 (2015): 1-24.

30. Beth Harry, Keith M. Sturgis, and Janette K. Klingner, "Mapping the Process: An Exemplar of Process and Challenge in Grounded Theory Analysis," Educational Researcher 34, no. 2 (2005): 3-13; Clara E. Hill et al., "Consensual Qualitative Research: An Update," Journal of Counseling Psychology 52, no. 2 (2005): 196-205.

31. Pearl, "Check It Out," 18-19; Saricks, Readers' Advisory Service, $40,42$.

32. Pearl, "Check It Out," 18-19.

33. Laura Ermi and Frans Mäyrä, "Fundamental Components of the Gameplay Experience: Analysing Immersion," in Proceedings of DiGRA 2005 Conference: Changing Views-Worlds in Play (2005): 1-14; Peter Vorderer, Christoph Klimmt, and Ute Ritterfeld, "Enjoyment: At the Heart of Media Entertainment," Communication Theory 14, no. 4 (2004): 388-408; Hunicke et al., "MDA: A Formal Approach," 1-5; Peter Vorderer, Tilo Hartmann, and Christoph Klimmt, "Explaining the Enjoyment of Playing Video Games: The Role of Competition," in Proceedings of the Second International Conference on Entertainment Computing (Pittsburgh: Carnegie Mellon University, 2003), 1-9.

34. Ross, "Finding without Seeking," 783-99.

35. Pearl, "Check It Out," 18-19.

36. Ermi and Mäyrä, "Fundamental Components of the Gameplay Experience," 1-14.

37. Ibid., 7.

38. Marvin E. Goldberg and Gerald J. Gorn, "Happy and Sad TV Programs: How They Affect Reactions to Commercials," Journal of Consumer Research 14, no. 3 (1987): 387-403; Catherine Sheldrick Ross and Mary K. Chelton, "Readers' Advisory: Matching Mood and Material," Library Journal 126, no. 2 (February 1, 2001): 52-55, Saricks, Readers' Advisory Service; Smita C. Banerjee et al., "The Role of Gender and Sensation Seeking in Film Choice: Exploring Mood and Arousal," Journal of Media Psychology 20, no. 3 (2008): 97-105; Xiao Hu, "Music and Mood: Where
Theory and Reality Meet," in Proceedings of the iConference 2010 (Urbana: University of Illinois at Urbana-Champaign, 2010), 115-22; Jin Ha Lee, Trent Hill, and Lauren Work, "What Does Music Mood Mean for Real Users?," in Proceedings of the 2012 iConference (New York: ACM, 2012), 112-119; Pearl, "Check It Out," 18-19; Stephanie Rossi, Jin Ha Lee, and Rachel Ivy Clarke, "Mood Metadata for Video Games and Interactive Media," in Proceedings of the 14th ACM/IEEE-CS Joint Conference on Digital Libraries (New York: ACM, 2014), 475-76.

39. Saricks, Readers' Advisory Service; Ross and Chelton, "Readers' Advisory."

40. Hu, "Music and Mood;" Lee, Hill, and Work, "What Does Music Mood Mean?"

41. Alan R. Hirsch, "Nostalgia: A Neuropsychiatric Understanding," in Advances in Consumer Research Volume 19, edited by John F. Sherry, Jr. and Brian Sternthal, 390-95 (Provo, UT: Association for Consumer Research, 1992).

42. Vorderer, Klimmt, and Ritterfeld, "Enjoyment," 388-408.

43. Bob Usherwood and Jackie Toyne, "The Value and Impact of Reading Imaginative Literature," Journal of Librarianship and Information Science 34, no. 1 (2002): 33-41.

44. Richard A. Bartle, Designing Virtual Worlds (Indianapolis: New Riders, 2004).

45. Pearl, "Check It Out," 18-19; Saricks, Readers' Advisory Service, 40, 42; Tom Warner, "Viewer's Advisory in the Digital Age," presentation slides, SlideShare, 2012, http://www.slideshare .net/SAS2012/viewers-advisory-slideshow-2012; Kaite Mediatore, "Reading with Your Ears: Readers' Advisory and Audio Books," Reference \& User Services Quarterly 42, no. 4 (2003): 318-23.

46. Ermi and Mäyrä, "Fundamental Components of the Gameplay Experience," 1-14.

47. Andrew K. Przybylski, C. Scott Rigby, and Richard M. Ryan, "A Motivational Model of Video Game Engagement," Review of General Psychology 14, no. 2 (2010): 154-66.

48. Hunicke et al., "MDA: A Formal Approach," 2.

49. Przybylski, Rigby, and Ryan, "A Motivational Model," 346.

50. Wyatt, The Readers' Advisory Guide to Nonfiction.

51. Hunicke et al., "MDA: A Formal Approach," 1-5; Dimitri Schuurman et al., "Fanboys, Competers, Escapists and TimeKillers: A Typology Based on Gamers' Motivations for Playing Video Games," in Proceedings of the 3rd International Conference on Digital Interactive Media in Entertainment and Arts (New York: ACM, 2008), 46-50.

52. Denis McQuail, Jay G. Blumler, and J. R. Brown, "The Television Audience: A Revised Perspective," in Media Studies: A Reader, edited by Paul Marris and Sue Thornham, 438-54 (New York: New York University Press, 1972); Leo Bogart, "The Mass Media and the Blue-Collar Worker," in Blue-Collar World: Studies of the American Worker, editedy by Arthur B. Shostak and William Gomberg, 416-27 (Englewood Cliffs, NJ: Prentice-Hall, 1964).

53. Joyce Saricks, "At Leisure: Whole-Collection Readers' Advisory," Booklist 107, no. 13 (2011): 25; Barry Trott and Tara Bannon Williamson, "Materials Matchmaking Articulating Whole Library Advisory," Reference \& User Services Quarterly 50, no. 3 (2011): 230-34; Wyatt, "Reading Maps Remake RA," 38-42. 